\title{
Rifabutin encapsulated in liposomes exhibits increased therapeutic activity in a model of disseminated tuberculosis
}

\author{
M.M. Gaspar ${ }^{\mathrm{a}, *}$, A. Cruz ${ }^{\mathrm{b}}$, A.F. Penha ${ }^{\mathrm{a}}$, J. Reymão ${ }^{\mathrm{a}}$, A.C. Sousa ${ }^{\mathrm{a}}$, C.V. Eleutério ${ }^{\mathrm{a}}$, \\ S.A. Domingues ${ }^{\text {b }}$, A.G. Fraga ${ }^{b}$, A. Longatto Filho ${ }^{\text {b }}$, \\ M.E.M. Cruz ${ }^{a, 1}$ J. Pedrosa ${ }^{b, 1}$ \\ a Unidade Novas Formas de Agentes Bioactivos, Departamento de Biotecnologia, Instituto Nacional de Engenharia Tecnologia e Inovação, \\ I.P., Estrada do Paço do Lumiar, 22, 1649-038 Lisboa, Portugal \\ ${ }^{\mathrm{b}}$ Life and Health Sciences Research Institute (ICVS), School of Health Sciences, University of Minho, \\ 4710-057 Braga, Portugal
}

Received 1 June 2007; accepted 4 August 2007

\begin{abstract}
Tuberculosis (TB) is a leading cause of death amongst infectious diseases. The low permeation of antimycobacterial agents and their difficult access to infected macrophages necessitate long-term use of high drug doses. Liposomes preferentially accumulate in macrophages, increasing the efficacy of antibiotics against intracellular parasites. In the present work, several rifabutin (RFB) liposomal formulations were developed and characterised and their in vivo profile was compared with free RFB following intravenous administration. With the RFB liposomal formulations tested, higher concentrations of the antibiotic were achieved in liver, spleen and lungs $24 \mathrm{~h}$ post administration compared with free RFB. The concentration of RFB in these organs was dependent on the rigidity of liposomal lipids. The liposomal RFB formulation prepared with dipalmitoyl phosphatidylcholine:dipalmitoyl phosphatidylglycerol (DPPC:DPPG) was the most effective and was selected for biological evaluation in a mouse model of disseminated TB. Compared with mice treated with free RFB, mice treated with the DPPC:DPPG RFB formulation exhibited lower bacterial loads in the spleen $\left(5.53 \log _{10}\right.$ vs. $\left.5.18 \log _{10}\right)$ and $\operatorname{liver}\left(5.79 \log _{10}\right.$ vs. $\left.5.41 \log _{10}\right)$. In the $\operatorname{lung}_{\text {, the }}$ level of pathology was lower in mice treated with encapsulated RFB. These results suggest that liposomal RFB is a promising approach for the treatment of extrapulmonary TB in human immunodeficiency virus co-infected patients.
\end{abstract}

(C) 2007 Elsevier B.V. and the International Society of Chemotherapy. All rights reserved.

Keywords: Liposomes; Rifabutin; Tuberculosis; HIV/AIDS patients; Drug delivery

\section{Introduction}

Tuberculosis (TB) is a leading cause of death amongst infectious diseases [1]. Furthermore, this re-emerging disease has become one of the most important infections affecting human immunodeficiency virus (HIV)-positive patients worldwide [2,3]. Although it is a more severe health problem in developing countries, TB has become a renewed threat in the Western world since the mid 1980s [4]. In view of this situation, the World Health Organization

\footnotetext{
* Corresponding author. Tel.: +351 21092 4733; fax: +351 217163636 .

E-mail address: Manuela.Gaspar@ineti.pt (M.M. Gaspar).

1 These authors share senior authorship.
}

declared TB a global public health emergency since 1993 [5].

Mycobacterium tuberculosis is a facultative intracellular parasite that after being phagocytosed by macrophages is able to survive and multiply within its host cell [6]. Development of an adaptive immune response mediated by T-lymphocytes, with the production of the macrophageactivating cytokine interferon-gamma (IFN $\gamma$ ) and the involvement of macrophages and lymphocytes in the formation of granulomata are crucial steps for the control of $M$. tuberculosis $[7,8]$.

Access of antimycobacterial agents to M. tuberculosis bacilli inside host macrophages is limited due to the low levels of drug permeation, making it difficult to achieve effective 
drug concentrations $[9,10]$. In addition, degradation of drugs may occur before they reach target tissues [11]. Therefore, conventional treatments for TB include daily therapy with high doses of antimycobacterial drugs for at least 6 months. These long treatment schedules are associated with severe side effects and result in poor compliance, one of the main reasons for the emergence of multidrug-resistant (MDR) strains, particularly in developing countries. Improvement of antimycobacterial therapy is therefore urgently required.

Although the development of new antimycobacterial drugs is an obvious and necessary strategy to fight TB, mechanisms to improve the efficacy of existing drugs could represent a faster approach. In this regard, improvement of the therapeutic index of existing antimycobacterial drugs should be considered, aimed at maximisation of its concentration at infected sites, reduction of toxic effects and reduction of treatment duration. Liposomes are one of the most thoroughly studied carrier systems and have been successively used for improving the efficacy of antibiotics directed against intramacrophage infectious agents whilst minimising adverse side effects $[12,13]$, including for the pathogenic mycobacteria Mycobacterium avium and M. tuberculosis [14-18].

The rationale behind the use of liposomes as antibiotic carrier systems in infections by intracellular parasites such as mycobacteria is based on their inherent tendency to be taken up by macrophages following systemic administration $[19,20]$. The physicochemical properties of liposomes play an important role in their in vivo fate. Thus, it is important to use a liposomal formulation that, following intravenous (i.v.) administration, does not destabilise, with concomitant release of their contents, before reaching their targets. Furthermore, drugs should only become bioavailable when the liposomes reach the target site and at a rate that would maintain the local levels of free drug at a therapeutic concentration [21].

Rifabutin (RFB), a rifamycin spiropiperidyl derivative, is a potent inhibitor of bacterial DNA-dependent RNA polymerases [22], with a broad spectrum of antimycobacterial activity [23-25]. RFB is in clinical use for the treatment of mycobacterial infections caused by $M$. tuberculosis, Mycobacterium leprae and M. avium, being particularly important in cases of MDR-TB given that development of resistance to this drug is low [26-31]. In previous work using a $M$. avium model of infection, a superior therapeutic effect of RFB was demonstrated when incorporated in liposomes compared with RFB in the free form [16]. In the present work, it was intended to investigate the therapeutic effect of liposomal RFB in an experimental disseminated $M$. tuberculosis infection with regard to RFB antimycobacterial activity as well as its effect on the progression of pathology. With this purpose in mind, we started by studying the in vivo fate of various RFB liposomal formulations in order to select the lipid composition able to deliver the antibiotic to the highest extent to the liver, spleen and lung, as these organs are the main targets of M. tuberculosis in this experimental model of infection.

\section{Materials and methods}

\subsection{Chemical products}

RFB was obtained from Pharmacy Biotech AB (Uppsala, Sweden). The following pure phospholipids were purchased from Lipoid (Ludwigshafen, Germany): egg phosphatidylcholine; phosphatidylglycerol; cholesterol (Chol); and poly(ethylene glycol) (PEG) covalently linked to distearoylphosphatidylethanolamine (DSPE-PEG). Dimyristoyl phosphatidylcholine, dimyristoyl phosphatidylglycerol, dipalmitoyl phosphatidylcholine (DPPC), dipalmitoyl phosphatidylglycerol (DPPG) and hydrogenated phosphatidylcholine (HPC) were obtained from Avanti Polar Lipids (Alabaster, $\mathrm{AL})$.

\subsection{Animals}

BALB/c mice (6-8 weeks old) were obtained from the Gulbenkian Institute of Science (Oeiras, Portugal) or from Charles River Laboratories (Barcelona, Spain). The animals were kept under standard hygiene conditions, fed commercial chow and given acidified drinking water ad libitum. All of the experimental procedures were carried out with the permission of the local laboratory committee.

\subsection{Preparation of RFB liposomal formulations}

Multilamellar vesicles composed of the selected lipids were prepared by a remote loading technique with an ammonium sulphate gradient according to Bolotin et al. [32] with some modifications. Briefly, the selected phospholipids were dissolved in chloroform and the mixture was dried by rotary evaporation of the organic solvent to a thin film under a nitrogen stream. The homogeneous film obtained was dispersed in a buffer solution containing $5 \%$ trehalose $(\mathrm{w} / \mathrm{v})$ and $60 \mathrm{mM}$ of ammonium sulphate ( $\mathrm{pH} 5$ ) in a phospholipid concentration of $32 \mu \mathrm{mol} / \mathrm{mL}$. The so-formed empty multilamellar vesicles were submitted to five freeze-thaw cycles by freezing the suspension in liquid nitrogen and thawing it in a $50^{\circ} \mathrm{C}$ water-bath. The dispersions were then sequentially filtered through polycarbonate membranes until an average vesicle size of $0.1 \mu \mathrm{m}$ was obtained using an extruder device (Lipex Biomembranes Inc., Vancouver, British Columbia, Canada). An ammonium sulphate gradient was created by replacement of the extraliposomal medium with a solution containing $150 \mathrm{mM}$ of sodium chloride and $10 \mathrm{mM}$ HEPES (pH 6.9) using a desalting column (Econo-Pac ${ }^{\circledR} 10$ DG; Bio-Rad Laboratories, Hercules, CA). A RFB solution, prepared in the above-mentioned buffer, was then incubated with unloaded liposomes for $1 \mathrm{~h}$ under stirring and at a temperature higher than the phase transition temperature of the respective lipid 
mixture. The non-encapsulated RFB was produced by ultracentrifugation at $250000 \times g$ for $3 \mathrm{~h}$ at $15^{\circ} \mathrm{C}$ in a Beckman LM-80 ultracentrifuge (Beckman Instruments, Inc., Fullerton, CA). The pellet was re-suspended in $10 \mathrm{mM}$ HEPES buffer with $150 \mathrm{mM}$ of sodium chloride ( $\mathrm{pH} 6.9$ ).

\subsection{Characterisation of RFB liposomal formulations}

RFB was quantified spectrophotometrically at $500 \mathrm{~nm}$ after disruption of the liposomes with ethanol [16]. The lipid content of the samples was determined using a colorimetric technique described by Rouser et al. [33]. Liposomes were characterised in terms of lipid composition and by the following encapsulation parameters: initial and final RFB to lipid ratios ((RFB/Lip)i and (RFB/Lip)f, respectively); and encapsulation efficiency defined as the percentage of [(RFB/Lip)f]/[(RFB/Lip)i]. RFB liposomes mean size was determined by dynamic light scattering in a Zetasizer $1000 \mathrm{HS}_{\mathrm{A}}$ (Malvern Instruments, Malvern, UK). As a measure of particle size distribution of the dispersion, the system reports the polydispersity index ranging from 0.0 for an entirely monodisperse sample up to 1.0 for a polydisperse suspension. The zeta potential was calculated by dynamic light scattering in a Zetasizer 2000 (Malvern Instruments).

\subsection{Determination of RFB by high-performance liquid chromatography (HPLC)}

\subsubsection{Chromatographic system}

Plasma and tissue levels of RFB were determined by HPLC according to Lau et al. [34] with adaptations. The HPLC system consisted of a System Gold (Beckman Instruments, Inc.), a Midas Spark 1.1 autoinjector and a Diode-Array 168 detector (Beckman Instruments, Inc.). The wavelength of this detector was set to $275 \mathrm{~nm}$. The analytical column was a LiChroCART ${ }^{\circledR}$ (250-4.6), Purospher $^{\circledR}$ Star RP-8 (5 $\mu \mathrm{m})$ (Merck, Darmstadt, Germany). The mobile phase consisted of $0.05 \mathrm{M}$ potassium dihydrogen phosphate and $0.05 \mathrm{M}$ sodium acetate $(\mathrm{pH}$ adjusted to 4.0 with acetic acid)-acetonitrile $(53: 47, \mathrm{v} / \mathrm{v})$ with a flow rate of $1 \mathrm{~mL} / \mathrm{min}$ at $25^{\circ} \mathrm{C}$.

\subsubsection{Preparation of standard solutions}

Standard solutions of RFB (100 $\mu \mathrm{g} / \mathrm{mL})$ were prepared by weighing the appropriate amount of bulk RFB and dissolving it in mobile phase. Further stock solutions were made by diluting the initial stock standard solutions with mobile phase. Three seven-point calibration curves ranging from $0.1 \mu \mathrm{g} / \mathrm{mL}$ to $2.5 \mu \mathrm{g} / \mathrm{mL}$, with a loop of $100 \mu \mathrm{L}$, were used for the quantification of RFB in plasma and tissues. A stock solution of $1.0 \mu \mathrm{g} / \mathrm{mL}$ was stored at $-30{ }^{\circ} \mathrm{C}$ and a sample of this stock solution was always injected together with the analysed samples to verify the precision of the obtained concentrations of RFB in samples and controls from their peak area concentration response.

\subsection{In vivo fate of RFB formulations}

\subsubsection{Biodistribution studies}

A single $20 \mathrm{mg} / \mathrm{kg}$ dose of free or liposomal RFB was injected intravenously into the lateral tail vein of four BALB/c mice per time point. Mice were sacrificed and blood was collected into heparinised tubes and stored at $-30^{\circ} \mathrm{C}$. The lung, spleen and liver of mice were removed and stored at $-70^{\circ} \mathrm{C}$.

\subsubsection{RFB extraction from blood and tissues}

RFB levels in blood and tissues were determined by HPLC after an extraction procedure according to Battaglia et al. [35] and Benedetti et al. [36] with adaptations. Briefly, $500 \mu \mathrm{L}$ of blood were mixed with $250 \mu \mathrm{L}$ of buffer $0.05 \mathrm{M}$ potassium dihydrogen phosphate and $0.05 \mathrm{M}$ sodium acetate $(\mathrm{pH}$ adjusted to 4.0 with acetic acid) and extracted twice with $1 \mathrm{~mL}$ of a dichloromethane:isooctane mixture (2:3, v/v) under stirring $(15 \mathrm{~min})$, followed by a centrifugation step at $1200 \times g$ for $10 \mathrm{~min}$ in a GPR centrifuge (Beckman Instruments, Inc.).

Liver, lung and spleen tissues were thawed and aliquots of ca. $100 \mathrm{mg}$ were weighed out for each sample and extracted twice with $2300 \mu \mathrm{L}$ of dichloromethane:isooctane mixture by mechanical shaking for $30 \mathrm{~min}$ at room temperature, followed by a centrifugation step at $1200 \times g$ for $10 \mathrm{~min}$ in a GPR centrifuge.

The organic extracts were pooled and evaporated to dryness under nitrogen. The residue was dissolved in $1500 \mu \mathrm{L}$ of mobile phase, filtered and then injected into the HPLC system.

To determine the efficiency of the extraction procedures, a known amount of RFB was added to blood and solid tissues removed from mice that had not received RFB administration and then submitted to the same above-mentioned extraction protocol.

\subsection{Biological evaluation in a M. tuberculosis infection model}

\subsubsection{Experimental infection, treatment and bacterial counts}

BALB/c mice were injected intravenously with $5 \times 10^{4}$ colony-forming units (CFU) of M. tuberculosis H37Rv. Treatment started 3 weeks after infection and consisted of administration of $20 \mathrm{mg} / \mathrm{kg}$ body weight of RFB in the free or liposomal form every 3 days over a 2 -week period, after which CFU counts were performed as described previously [7].

\subsubsection{Quantitative real-time polymerase chain reaction (PCR) analysis}

Liver tissue from infected mice was collected and frozen in TRIzol reagent (Invitrogen, San Diego, CA). Total RNA was extracted and submitted to reverse transcription using SuperScript $^{\circledR}$ II and Oligo(dT) (Invitrogen) according to 
the manufacturer's instructions. cDNA was subjected to real-time PCR for quantification of hypoxanthine phosphoribosyltransferase and IFN $\gamma$ using the LightCycler ${ }^{\circledR}$ instrument (Roche, Indianapolis, IN) as previously described [37].

\subsubsection{Histology}

Representative portions of lung tissue were harvested, fixed in $10 \%$ buffered formalin and processed for standard histological analysis. Sections were stained with haematoxylin and eosin for evaluation of pathological changes.

\subsection{Statistical analysis}

The results are given as mean \pm standard deviation. Statistical significance was calculated using the Student's $t$-test. Values of $P<0.05$ were considered significant.

\section{Results}

\subsection{RFB liposomes: physicochemical characterisation}

The in vivo fate of RFB in the free form or encapsulated in liposomes was evaluated in non-infected mice following i.v. administration. For this purpose, $0.1 \mu \mathrm{m}$ mean size liposomes were prepared with phospholipids of different phase transition temperatures $\left(T_{\mathrm{c}}\right)$, with and without added PEG (Table 1). The liposomal formulations had a (RFB/Lip)f of $40-62 \mathrm{nmol} / \mu \mathrm{mol}$ of lipid, thus allowing comparative in vivo studies at similar liposomal lipid doses. Two types of liposomes were prepared: conventional liposomes made with natural or synthetic phospholipids and liposomes incorporating the PEG polymer covalently linked to DSPE (DSPE-PEG), henceforth called PEG liposomes.

\subsection{In vivo fate of $R F B$ formulations}

\subsubsection{Biodistribution studies}

Biodistribution profiles of RFB liposomal formulations following i.v. administration were assayed. The influence of liposomal composition on RFB targeting to the spleen, liver and lung as well as on RFB blood concentration was evaluated over time in comparison with free RFB. The biodistribution profiles of various RFB liposomal formulations indicate that the liver, lung and, particularly, the spleen constitute the main targeted organs of liposomes (Fig. 1). For the liver (Fig. 1A), no relevant differences in RFB concentrations were found at $2 \mathrm{~h}$ and $6 \mathrm{~h}$ post injection. However, at $24 \mathrm{~h}$ post injection detectable amounts of RFB in the liver were only found in mice treated with RFB incorporated into liposomes, ranging from $2 \mu \mathrm{g} / \mathrm{g}$ to a maximum of $4 \mu \mathrm{g} / \mathrm{g}$ of organ for the DPPC:DPPG formulation. For the spleen (Fig. 1B), a very high amount of RFB was found at $2 \mathrm{~h}$ post injection in mice that received RFB encapsulated in DPPC:DPPG liposomes ( $81 \mu \mathrm{g} / \mathrm{g}$ of organ). However, at $6 \mathrm{~h}$ post injection the values were similar for all RFB formulations, ranging from $5 \mu \mathrm{g} / \mathrm{g}$ to $9 \mu \mathrm{g} / \mathrm{g}$ of organ. Importantly, as observed in the liver, at $24 \mathrm{~h}$ post injection detectable RFB values were only achieved for liposomal formulations. Higher values were found in mice treated with liposomal formulations prepared with phospholipids of high $T_{\mathrm{c}}$ (DPPC:DPPG, HPC:Chol:DSPE-PEG and DPPC:PEG). For the lung (Fig. 1C), the RFB formulation prepared with DPPC:DPPG showed the highest amount of non-metabolised RFB at $2 \mathrm{~h}$ post injection $(27 \mu \mathrm{g} / \mathrm{g}$ of organ). At $24 \mathrm{~h}$ post injection, RFB was only detected in the lung of mice treated with lipid mixtures of higher $T_{\mathrm{c}}$, namely DPPC:DPPG, HPC:Chol:DSPE-PEG and DPPC:PEG, with lung concentrations ranging from $2 \mu \mathrm{g} / \mathrm{g}$ to $4 \mu \mathrm{g} / \mathrm{g}$ of organ. Finally, the concentration of RFB in total blood $2 \mathrm{~h}$ post injection was higher in mice treated with phospholipids of higher $T_{\mathrm{c}}$, namely DPPC:DPPG and HPC:Chol:DSPE-PEG liposomes, compared with free RFB or the other RFB formulations (Fig. 1D). The higher blood residence time of RFB when encapsulated into liposomes made with phospholipids of long and saturated lipid mixtures is in accordance with the literature $[38,39]$.

Overall, our results show more efficient delivery to the liver, spleen and lung, of RFB encapsulated in liposomes prepared with phospholipids of high $T_{\mathrm{c}}$. In addition, the lipid composition DPPC:DPPG most effectively delivered RFB to these organs. This formulation was therefore selected for biological evaluation in a model of disseminated TB

Table 1

Physicochemical properties of rifabutin (RFB) liposomal formulations ${ }^{\mathrm{a}}$

\begin{tabular}{lcllll}
\hline Lipid composition $(\mathrm{molar}$ ratio $)\left[T_{\mathrm{c}}\right]$ & $(\mathrm{RFB} / \mathrm{Lip}) \mathrm{i}(\mathrm{nmol} / \mu \mathrm{mol})$ & $(\mathrm{RFB} / \mathrm{Lip}) \mathrm{f}(\mathrm{nmol} / \mu \mathrm{mol})$ & $\mathrm{EE}(\%)$ & $\emptyset(\mu \mathrm{m})(\mathrm{PI})$ & Zeta potential $(\mathrm{mV})$ \\
\hline PC:PG $(7: 3)\left[-6^{\circ} \mathrm{C}\right] /\left[-6^{\circ} \mathrm{C}\right]$ & $63 \pm 8$ & $62 \pm 8$ & $102 \pm 10$ & $0.10(<0.2)$ & $-33 \pm 2$ \\
DMPC:DMPG $(7: 3)\left[+23^{\circ} \mathrm{C}\right] /\left[+23^{\circ} \mathrm{C}\right]$ & $101 \pm 5$ & $55 \pm 3$ & $55 \pm 6$ & $0.10(<0.2)$ & $-31 \pm 3$ \\
DPPC:DPPG $(7: 3)\left[+42^{\circ} \mathrm{C}\right] /\left[+42^{\circ} \mathrm{C}\right]$ & $64 \pm 4$ & $46 \pm 6$ & $72 \pm 5$ & $0.10(<0.2)$ & $-33 \pm 1$ \\
PC:Chol:PEG $(1.85: 1: 0.15)\left[-6^{\circ} \mathrm{C}\right] /[] /[]$ & $71 \pm 4$ & $60 \pm 8$ & $90 \pm 10$ & $0.13(<0.2)$ & $-4 \pm 1$ \\
DPPC:PEG $(2.85: 0.15)\left[+42^{\circ} \mathrm{C}\right] /[]$ & $82 \pm 3$ & $40 \pm 1$ & $49 \pm 5$ & $0.14(<0.2)$ & $-5 \pm 1$ \\
HPC:Chol:PEG $(1.85: 1: 0.15)\left[+58^{\circ} \mathrm{C}\right] /[] /[]$ & $55 \pm 3$ & $36 \pm 2$ & $64 \pm 3$ & $0.12(<0.2)$ & $-3 \pm 2$ \\
\hline
\end{tabular}

$T_{\mathrm{c}}$ : phase transition temperature of phospholipid; (RFB/Lip)i: initial RFB to lipid ratio; (RFB/Lip)f: final RFB to lipid ratio; EE: encapsulation efficiency $\{=$ [(RFB/Lip)f]/[(RFB/Lip)i] $\times 100\} ; \varnothing$ : mean diameter of liposomes; PI: polydispersity index; PC: egg phosphatidylcholine; PG: phosphatidylglycerol; DMPC: dimyristoyl phosphatidylcholine; DMPG: dimyristoyl phosphatidylglycerol; DPPC: dipalmitoyl phosphatidylcholine; DPPG: dipalmitoyl phosphatidylglycerol; Chol: cholesterol; PEG: poly(ethylene glycol); HPC: hydrogenated phosphatidylcholine; []: not applicable.

${ }^{a}$ Initial lipid concentration, $32 \mu \mathrm{mol} / \mathrm{mL}$; (RFB/Lip)i, 50-100 nmol RFB per $\mu \mathrm{mol}$ of lipid. 

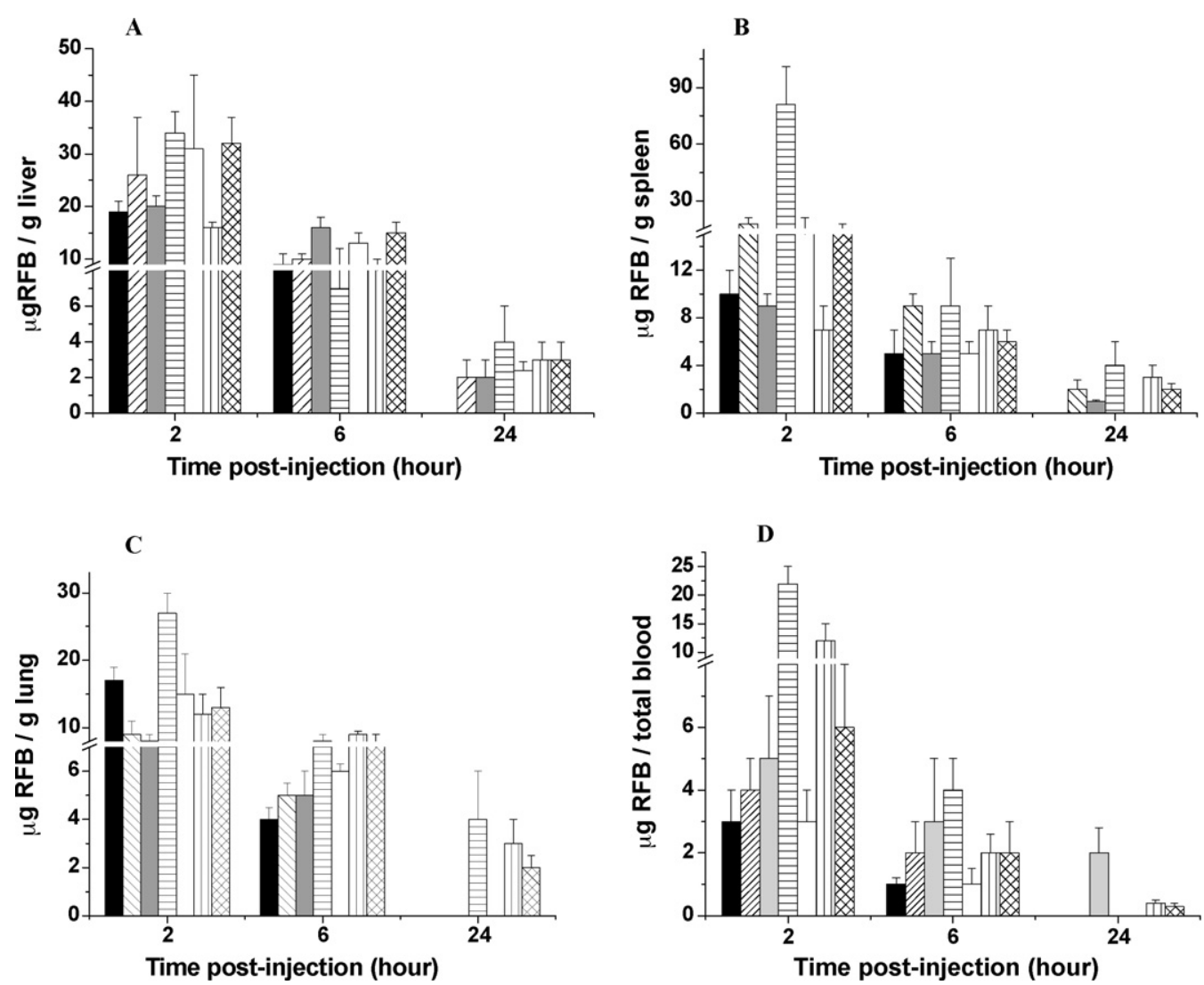

Fig. 1. Pharmacokinetics and biodistribution of rifabutin (RFB) formulations as measured by non-metabolised RFB in BALB/c mice in (A) liver ( $\mu \mathrm{g} / \mathrm{g}$ liver); (B) spleen ( $\mu \mathrm{g} / \mathrm{g}$ spleen); (C) lung ( $\mu \mathrm{g} / \mathrm{g}$ lung); and (D) total blood ( $\mu \mathrm{g} / \mathrm{total}$ blood) following intravenous administration of the following formulations (dose $20 \mathrm{mg} / \mathrm{kg}$ RFB): free RFB (black bar); PC:PG (bar with diagonal lines); DMPC:DMPG (grey bar); DPPC:DPPG (bar with horizontal lines); PC:Chol:DSPE-PEG (white bar); HPC:Chol:DSPE-PEG (bar with vertical lines); and DPPC:PEG (bar with grid). Liposomes mean size was $0.1 \mu \mathrm{m}$. The results are expressed as mean \pm standard deviation ( $n=4$ mice per selected time and per RFB formulation). PC, egg phosphatidylcholine; PG, phosphatidylglycerol; DMPC, dimyristoyl phosphatidylcholine; DMPG, dimyristoyl phosphatidylglycerol; DPPC, dipalmitoyl phosphatidylcholine; DPPG, dipalmitoyl phosphatidylglycerol; Chol, cholesterol; PEG, poly(ethylene glycol); DSPE-PEG, PEG covalently linked to distearoyl-phosphatidylethanolamine; HPC, hydrogenated phosphatidylcholine.

in which the liver, spleen and lung are the major target organs.

\subsection{Biological evaluation of RFB formulations in a model of M. tuberculosis disseminated infection}

\subsubsection{Bacterial burdens after treatment with free or liposomal RFB}

To assess the antimycobacterial activity of encapsulated versus free RFB in vivo, mice were infected intravenously with $4.7 \log _{10}$ CFU of $M$. tuberculosis. Before treatment was started at 3 weeks post infection, bacillary burdens had increased in all organs (data not shown). After a 2-week treatment period, a significant reduction in the bacterial loads of all primary target organs was observed for treated mice compared with untreated mice (Fig. 2). No significant differences in bacterial counts were found between the lungs of mice treated with free or liposomal RFB (Fig. 2). However, administration of RFB encapsulated in DPPC:DPPG liposomes resulted in a significant reduction in the number of bacilli recovered both from the spleen and liver compared with administration of free RFB (Fig. 2).

\subsubsection{IFN $\gamma$ expression in the liver after treatment with free or liposomal $R F B$}

Production of IFN $\gamma$ by T-cells, induced upon M. tuberculosis infection, plays a protective role through macrophage activation [6]. Therefore, we assessed relative IFN $\gamma$ mRNA expression in the liver by real-time PCR to determine whether the reduction in bacterial burdens found in the organs of RFBtreated mice was associated with an altered IFN $\gamma$ profile. Compared with untreated mice, expression of IFN $\gamma$ was not different in mice treated with free RFB but was significantly decreased in the livers of mice treated with liposomal RFB (Fig. 3). This result is in accordance with the reduced number of bacteria present in the liver of these mice and with the associated reduced level of microbial inflammatory stimulus.

\subsubsection{Histological analysis of lungs after treatment with free or liposomal $R F B$}

As noted above, no significant differences were observed in the number of bacilli found in the lungs of mice treated with encapsulated RFB compared with treatment with free drug. However, the outcome of the disease in M. tuberculosisinfected lung depends not only on the bacterial burden but 

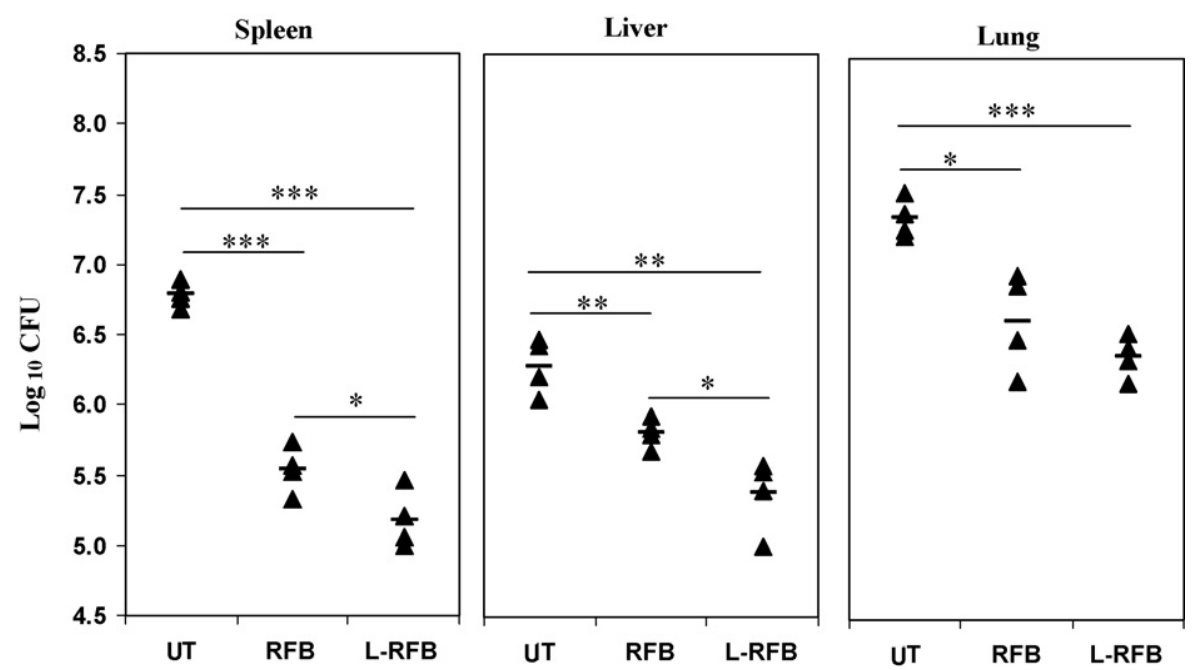

Fig. 2. Bacterial burdens following treatment with liposomal or free rifabutin (RFB). BALB/c mice were infected intravenously with 4.7 log 10 colony-forming units (CFU) of Mycobacterium tuberculosis. At 3 weeks after infection, the experimental groups were either left untreated (UT) or treated with free RFB or with liposomal RFB (L-RFB) over a 2-week period. The therapeutic effects of the treatments were evaluated in the primary target organs by CFU counts at the end of treatment ( 5 weeks after infection). The results are expressed as mean \pm standard deviation $(n=5$ mice). Results are from one experiment representative of three independent experiments. Statistical significance was determined by Student's $t$-test: $* P<0.05 ; * * P<0.01 ; * * * P<0.005$.

also on the characteristics of the inflammatory response, which can be associated with tissue damage [40]. We therefore analysed lung tissue sections to determine the effect of treatment with RFB on histopathology. The lung of untreated mice showed an intense acute inflammatory response (Fig. 4A) containing numerous neutrophils, correlating with the high $\mathrm{CFU}$ counts. In mice treated with

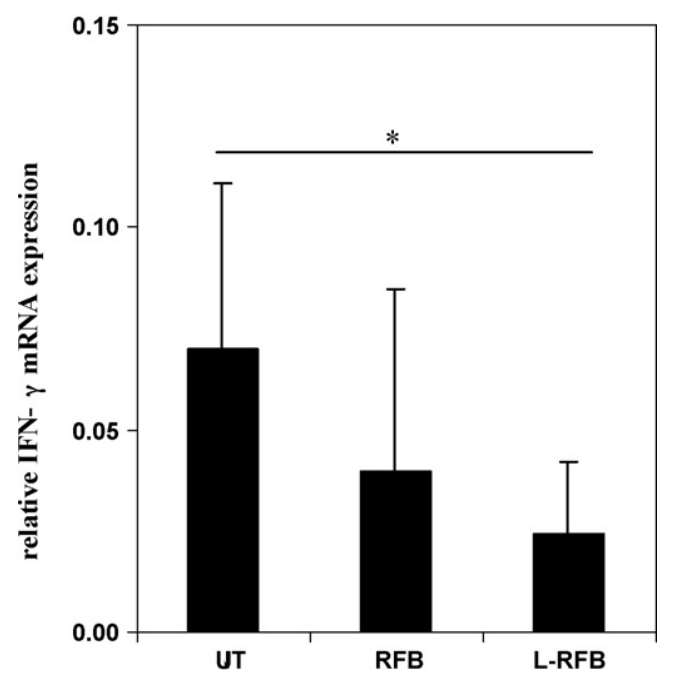

Fig. 3. Expression of interferon-gamma (IFN $\gamma$ ) in livers of infected mice. $\mathrm{BALB} / \mathrm{c}$ mice were infected intravenously with $4.7 \log _{10}$ colony-forming units of Mycobacterium tuberculosis. At 3 weeks after infection, the experimental groups were either left untreated (UT) or treated with free rifabutin (RFB) or with liposomal RFB (L-RFB). The relative expression of IFNy mRNA was assessed by real-time polymerase chain reaction in the liver at the end of treatment. The results are expressed as mean \pm standard deviation $(n=5)$. Statistical significance was determined using Student's $t$-test: $* P<0.05$. free RFB, the cellular infiltrate was milder, consisting of lymphocytes, macrophages and epithelioid cells, with numerous granulomata scattered throughout the lung parenchyma (Fig. 4B). In the lung of mice treated with liposomal RFB, the inflammatory infiltrate also had a mononuclear profile. Importantly, this inflammatory response was diminished compared with that of mice treated with free RFB and was associated with a decreased number of granulomata that were restricted to the perivascular area (Fig. 4C). Therefore, even though no significant differences were found in the bacterial loads in the lung of mice treated with either free or liposomal RFB, histopathology shows that treatment with encapsulated RFB is associated with lower levels of lung inflammation.

\section{Discussion}

The rationale for the association of RFB with liposomes, as tested here, is to achieve an increased therapeutic effect of this second-line antimycobacterial drug through its preferential accumulation in infected macrophages present in the main target organs of $M$. tuberculosis whilst reducing its toxicity $[41,42]$ and the periodicity of the treatment regimen, which may contribute to compliance in long-term treatment regimens. Taking this into consideration, different liposomal formulations were developed and their in vivo fate was evaluated by quantifying the non-metabolised RFB following systemic administration. The biodistribution profiles of RFB liposomal formulations indicate that the liver and spleen constitute the main targeted organs of liposomes. In fact, $24 \mathrm{~h}$ post injection it was only possible to detect non-metabolised RFB in both organs in mice receiving RFB in the liposomal form. The quantity of non-metabolised RFB detected in the lung was lower than the amounts observed in the 

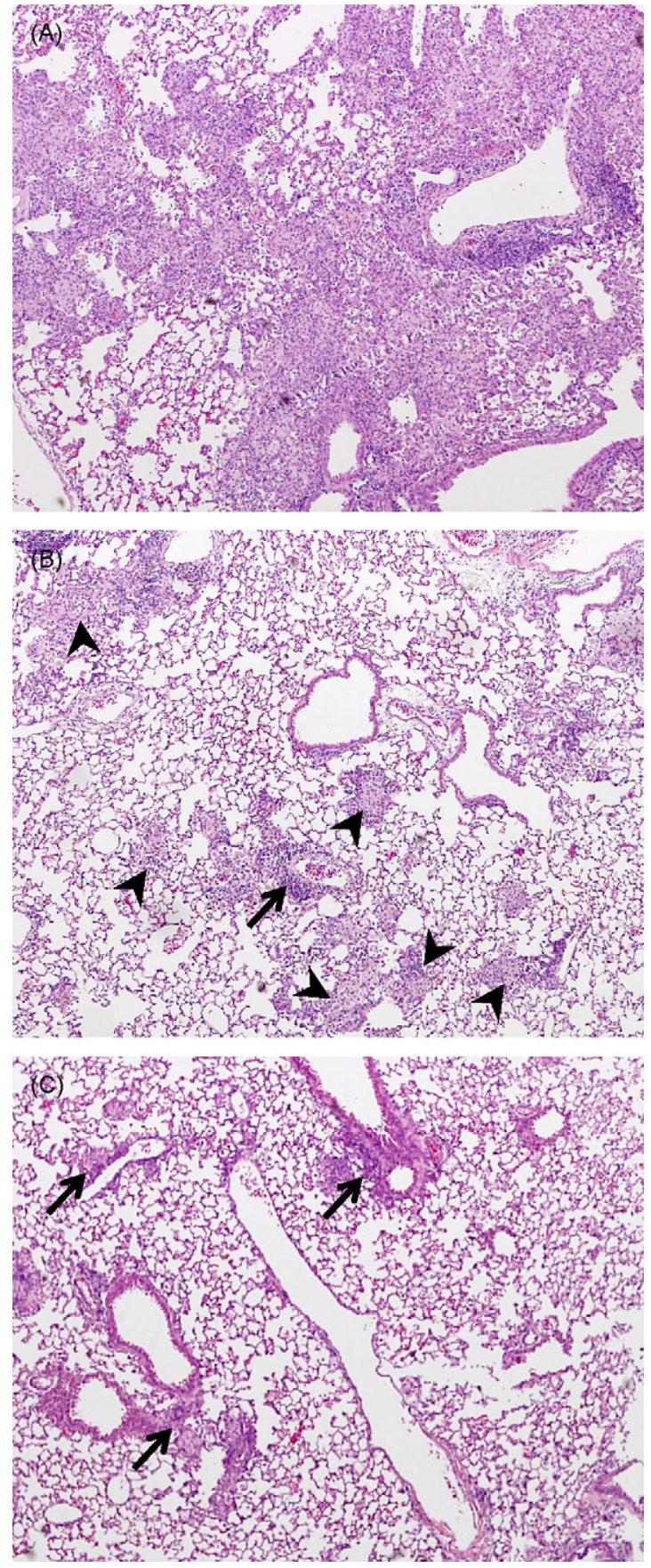

Fig. 4. Lung histopathology in infected mice. BALB/c mice were infected intravenously with $4.7 \log _{10}$ colony-forming units of Mycobacterium tuberculosis. At 3 weeks after infection, the experimental groups were either left untreated (A) or treated with free rifabutin (RFB) (B) or with encapsulated RFB (C). The lungs of mice from the different experimental groups were harvested after the end of treatment and serial tissue sections were stained with haematoxylin and eosin (magnification 40×). (A) An intense acute inflammatory cellular response in the lung of untreated mice. (B, C) The cellular infiltrates were milder, consisting mostly of mononuclear cells. The granuloma distribution between the two treatments differed. In (B), granulomata were predominantly found scattered throughout the parenchyma (arrowheads), whilst in (C) granulomata were restricted to the perivascular area (arrows). liver and spleen and these levels were lipid compositiondependent. The observation that RFB liposomal formulations prepared with phospholipids of higher $T_{\mathrm{c}}$ resulted in the highest amounts of non-metabolised RFB in the lung is in accordance with the higher stability of these liposomes. As extensively described in the literature, the higher stability of liposomes results in lower drug release as well as alteration of the biodistribution profile of the drug within liposomes $[21,43]$. In the present work, it was only possible to detect non-metabolised RFB $24 \mathrm{~h}$ post injection for RFB liposomes prepared with rigid phospholipids. In the future, efforts should be pursued to develop other liposomal formulations to optimise the targeting of antimycobacterial agents to the lung.

Based on the biodistribution studies, the rigid phospholipids DPPC and DPPG were selected for encapsulating RFB to evaluate comparatively the therapeutic effect with free RFB in a disseminated M. tuberculosis model of infection. Administration of free or liposomal RFB to mice infected with $M$. tuberculosis resulted in a significant decrease in the bacterial loads in all the target organs analysed. Additionally, a statistically significant higher antimycobacterial effect of liposomal RFB was achieved in comparison with free RFB in liver and spleen.

Encapsulation of RFB in liposomes, in addition to improving the efficacy of the antibiotic, also decreases the potentially damaging inflammatory responses in infected organs, namely in the lung, where no statistically significant differences in mycobacterial loads were found between mice treated with free or liposomal RFB.

In our model of disseminated infection, increased reduction of bacterial burdens in mice treated with liposomal RFB was achieved in the liver and spleen but not in the lung, which is the main target organ of M. tuberculosis in immunocompetent hosts. For the treatment of pulmonary TB, it would be of interest to test administration by the aerogenic route of liposome-encapsulated antimycobacterial drugs. However, HIV-induced immunosuppression modifies the clinical presentation of TB, resulting in an increased occurrence of extrapulmonary $M$. tuberculosis infections, including disseminated forms of the disease [44]. Our results showing that RFB encapsulated in liposomes has a superior therapeutic effect in the spleen and liver suggest that encapsulated RFB could be a potential approach for more effective control of extrapulmonary TB in HIV/acquired immune deficiency syndrome (AIDS) patients. There is a need for better treatment regimens for the increasing number of cases of HIV/M. tuberculosis co-infection. The combination of highly active antiretroviral therapy (HAART) with the standard first-line TB drug rifampicin has been described to lead to subtherapeutic concentrations of antiretroviral drugs through activation of the hepatic cytochrome P450 system [44,45]. Alternatively to rifampicin, RFB can be used, with an appropriate dose reduction, in combination with HAART [44,45], which could be achieved through encapsulation in liposomes. Finally, the emergence of MDR tuberculosis in HIV/AIDS patients is 
one of the major concerns among public health entities [46] and also justifies the therapeutic use of encapsulated RFB in patients infected with M. tuberculosis strains resistant to rifampicin but not to RFB [28,46].

In conclusion, DPPC:DPPG RFB liposomes were the most effective tested formulation to deliver RFB to the liver, spleen and lung. The superior therapeutic effect of this RFB liposomal formulation in the mouse model of disseminated TB compared with non-incorporated antibiotic makes such a therapeutic approach a good candidate for the treatment of TB in patients co-infected with HIV.

\section{Acknowledgments}

We thank Drs A.G. Castro, M.T. Silva and M. CorreiaNeves for reading of the manuscript, and Dr Goreti Pinto and Luís Martins for laboratory assistance.

Funding: This work was supported by grants from FCT (POCTI/FCB/36416/99) and from the Health Services of FCG. Fellowships were granted by FCT (SFRH/BD/ 9624/2002- GABBA Program to A. Cruz and SFRH/BD/ $15911 / 2005$ to A.G. Fraga).

Competing interests: None declared.

Ethical approval: Animal handling complied fully with institutional policy.

\section{References}

[1] World Health Organization. Global tuberculosis control: surveillance, planning, financing. Geneva, Switzerland: World Health Organization; 2006.

[2] Pozniak AL, Miller R, Ormerod LP. The treatment of tuberculosis in HIV-infected persons. AIDS 1999;14:435-45.

[3] Reid A, Scano F, Getahun H, et al. Towards universal access to HIV prevention, treatment, care, and support: the role of tuberculosis/HIV collaboration. Lancet Infect Dis 2006;6:483-95.

[4] Bloom BR, Murray CJ. Tuberculosis: commentary on a reemergent killer. Science 1992;257:1055-64.

[5] World Health Organization. WHO declares tuberculosis a global emergency. Soz Praventivmed 1993;38:251-2.

[6] Flynn JL, Chan J. Immunology of tuberculosis. Annu Rev Immunol 2001;19:93-129.

[7] Cooper AM, Dalton DK, Stewart TA, Griffin JP, Russell DG, Orme IM. Disseminated tuberculosis in interferon $\gamma$ gene-disrupted mice. J Exp Med 1993;178:2243-7.

[8] Pearl JE, Saunders B, Ehlers S, Orme IM, Cooper AM. Inflammation and lymphocyte activation during mycobacterial infection in the interferon-gamma-deficient mouse. Cell Immunol 2001;211:4350.

[9] Gürsoy A. Liposome-encapsulated antibiotics: physicochemical and antibacterial properties, a review. STP Pharma Sci 2000;10:28591.

[10] Schiffelers RM, Bakker-Woudenberg IAJM. Innovations in liposomal formulations for antimicrobial therapy. Expert Opin Ther Pat 2003;13:1127-40.

[11] Yanagihara K. Design of anti-bacterial drug and anti-mycobacterial drug for drug delivery system. Curr Pharm Des 2002;8:475-82.

[12] Bakker-Woudenberg IA, ten Kate MT, Stearne-Cullen LE, Woodle MC. Efficacy of gentamicin or ceftazidime entrapped in lipo- somes with prolonged blood circulation and enhanced localization in Klebsiella pneumoniae-infected lung tissue. J Infect Dis 1995;171: 938-47.

[13] Fielding RM, Moon-McDermott L, Lewis RO, Horner MJ. Pharmacokinetics and urinary excretion of amikacin in low-clearance unilamellar liposomes after a single or repeated intravenous administration in the rhesus monkey. Antimicrob Agents Chemother 1999;43:503-9.

[14] Adams LB, Sinha I, Franzblau SG, Krahenbuhl JL, Mehta RT. Effective treatment of acute and chronic murine tuberculosis with liposome-encapsulated clofazimine. Antimicrob Agents Chemother 1999;43:1638-43.

[15] Fielding RM, Lasic DD. Liposomes in the treatment of infectious diseases. Expert Opin Ther Pat 1999;9:1679-88.

[16] Gaspar MM, Neves S, Portaels F, Pedrosa J, Silva MT, Cruz MEM. Therapeutic efficacy of liposomal rifabutin in a Mycobacterium avium model of infection. Antimicrob Agents Chemother 2000;44:2424 30.

[17] Labana S, Pandey R, Sharma S, Khuller GK. Chemotherapeutic activity against murine tuberculosis of once weekly administered drugs (isoniazid and rifampicin) encapsulated in liposomes. Int $\mathbf{J}$ Antimicrob Agents 2002;20:301-4.

[18] Pinto-Alphandary H, Andremont A, Couvreur P. Targeted delivery of antibiotics using liposomes and nanoparticles: research and applications. Int J Antimicrob Agents 2000;13:155-68.

[19] Couvreur P, Vauthier C. Nanotechnology: intelligent design to treat complex disease. Pharm Res 2006;23:1417-50.

[20] Couvreur P, Fattal E, Andremont A. Liposomes and nanoparticles in the treatment of intracellular bacterial infections. Pharm Res 1991;8:1079-86.

[21] Allen TM, Cullis PR. Drug delivery systems: entering the mainstream. Science 2004;303:1818-22.

[22] Barluenga J, Aznar F, García A, Cabal M, Palacios J, Menéndez M. New rifabutin analogs: synthesis and biological activity against Mycobacterium tuberculosis. Bioorg Med Chem Lett 2006;16: 5717-22.

[23] O'Brien RJ, Lyle MA, Zinder DE. Rifabutin (ansamycin LM 427): a new rifamycin-S derivative for the treatment of mycobacterial diseases. Rev Infect Dis 1987;9:519-30.

[24] Orme IM. Antimycobacterial activity in vivo of LM427 (rifabutin). Am Rev Respir Dis 1988;138:1254-7.

[25] Saito H, Sato K, Tomioka H. Comparative in vitro and in vivo activity of rifabutin and rifampicin against Mycobacterium avium complex. Tubercle 1988;69:187-92.

[26] Benson CA, Williams PL, Cohn DL, et al. Clarithromycin or RFB alone or in combination for primary prophylaxis of Mycobacterium avium complex disease in patients with AIDS. J Infect Dis 2000;181:128997.

[27] Grassi C, Peona V. Use of rifabutin in the treatment of pulmonary tuberculosis. Clin Infect Dis 1996;22(Suppl. 1):S50-4.

[28] Li J, Munsiff SS, Driver CR, Sackoff J. Relapse and acquired rifampin resistance in HIV-infected patients with tuberculosis treated with rifampin- or rifabutin-based regimens in New York City, 1997-2000. Clin Infect Dis 2005;41:83-91.

[29] Nightingale SD, Cameron DW, Gordin FM, et al. Two controlled trials of rifabutin prophylaxis against Mycobacterium avium complex infection in AIDS. N Engl J Med 1993;329:828-33.

[30] Siegal FP. Rifabutin prophylaxis for Mycobacterium avium complex infection in patients with AIDS. Clin Infect Dis 1996;22(Supp1. 1):S23-32.

[31] Sullam PM. Rifabutin therapy for disseminated Mycobacterium avium complex infection. Clin Infect Dis 1996;22(Suppl. 1):S37-42.

[32] Bolotin EM, Cohen R, Bar LK, et al. Ammonium sulfate gradients for efficient and stable remote loading of amphipathic weak bases into liposomes and ligandoliposomes. J Liposome Res 1994;4:455-79.

[33] Rouser G, Fleischer S, Yamamoto A. Two dimensional thin layer chromatographic separation of polar lipids and determination of 
phospholipids by phosphorus analysis of spots. Lipids 1970;5: 494-6.

[34] Lau YY, Anson GD, Carel BJ. Determination of rifabutin in human plasma by high-performance liquid chromatography with ultraviolet detection. J Chromatogr B Biomed Appl 1996;676:125-30.

[35] Battaglia R, Pianezzola E, Salgarollo G, Zini G, Benedetti MS. Absorption, disposition and preliminary metabolic pathway of ${ }^{14} \mathrm{C}$-rifabutin in animals and man. J Antimicrob Chemother 1990;26:813-22.

[36] Benedetti MS, Pianezzola E, Brianceshi G, et al. An investigation of the pharmacokinetics and autoinduction of rifabutin metabolism in mice treated with $10 \mathrm{mg} / \mathrm{kg} /$ day for 8 weeks. J Antimicrob Chemother 1995;36:247-51.

[37] Teixeira L, Botelho AS, Batista AR, et al. Analysis of the immune response to Neospora caninum in a model of intragastric infection in mice. Parasite Immunol 2007;29:23-36.

[38] Kirby C, Clarke J, Gregoriadis G. Effect of cholesterol content of small unilamellar liposomes on their stability in vitro and in vivo. Biochem J 1980;186:591-8.

[39] Senior J, Crawley JCW, Gregoriadis G. Tissue distribution of liposomes exhibiting long half-lives in the circulation after intravenous injection. Biochim Biophys Acta 1985;839:1-8.
[40] Dannenberg Jr AM. Pathogenesis of pulmonary tuberculosis: an interplay of time-damaging and macrophage-activating immune responses. Dual mechanisms that control bacillary multiplication. In: Bloom BR, editor. Tuberculosis: pathogenesis, protection, and control. Washington, DC: ASM Press; 1994. p. 459-83.

[41] Dye C, Williams BG. Criteria for the control of drug-resistant tuberculosis. Proc Natl Acad Sci USA 2000;97:8180-5.

[42] Lee SK, Tan KK, Chew SK, Snodgrass I. Multidrug-resistant tuberculosis. Ann Acad Med Singapore 1995;24:442-6.

[43] Senior JH. Fate and behavior of liposomes in vivo: a review of controlling factors. Crit Rev Ther Drug Carrier Syst 1987;2:123-93.

[44] Aaron L, Saadoun D, Calatroni I, et al. Tuberculosis in HIVinfected patients: a comprehensive review. Clin Microbiol Infect 2004; 10:388-98.

[45] Breen RA, Swaden L, Ballinger J, Lipman MC. Tuberculosis and HIV co-infection: a practical therapeutic approach. Drugs 2006; 66:2299-308.

[46] Dye C. Global epidemiology of tuberculosis. Lancet 2006;367:93840. 